\title{
Biosensor for Rapid and Sensitive Detection of Influenza Virus
}

\author{
Jong Min Yang, Kyeong Rok Kim, and Chang Sup Kim
}

Received: 20 June 2018 / Revised: 24 August 2018 / Accepted: 27 August 2018

(C) The Korean Society for Biotechnology and Bioengineering and Springer 2018

\begin{abstract}
Influenza viruses continue to threaten human life, causing considerable damage socially and economically. To reduce influenza-related morbidity and mortality, there is an immediate requirement to develop efficient and effective tools to detect the virus. Several methods are currently employed for diagnosing influenza infections in humans, including viral culture, polymerase chain reaction (PCR), and immunoassay. In addition, biosensors are being developed to improve the limitations of the conventional methods. In this article, we review the current progress in investigative techniques, including the development of biosensors having high sensitivity and selectivity and shorter detection time.
\end{abstract}

Keywords: influenza diagnostics, electrochemical biosensor, optical biosensor, mass-based biosensor

\section{Introduction}

The influenza viruses are enveloped negative-stranded RNA viruses belonging to the Orthomyxoviridae family. Depending on the differences in nucleoprotein and matrix proteins, the viruses are divided into three types: A, B, and C. Influenza A virus contains two antigenic surface glycoproteins, hemagglutinin (HA) and neuraminidase (NA). The HA glycoprotein is responsible for binding to a host cell and the NA glycoproteins play important roles for increasing the access of viruses to the host cell, replicating the viruses, and facilitating the release of newly synthesized viruses [1-4].

Jong Min Yang ${ }^{\dagger}$, Kyeong Rok Kim ${ }^{\dagger}$, Chang Sup Kim*

Graduate School of Biochemistry, Yeungnam University, Gyeongsan 38541, Korea

Tel: +82-53-810-3046; Fax: +82-53-810-4619

E-mail: cskim1409@ynu.ac.kr

\footnotetext{
These authors contributed equally to this work.
}

The subtype of the A virus is further classified according to the antigenic properties of $18 \mathrm{H}(1-18)$ and $11 \mathrm{~N}(1-11)$ glycoproteins [5-8]. Serious antigenic drift of influenza viruses occurs since the antigenic portions of $\mathrm{H}$ and $\mathrm{N}$ glycoproteins are easily exchangeable [9]. Sometimes new strains or subtypes emerge through the combination of two or more influenza viruses of different origins [5]. This reassortment results in the occurrence of highly mortal avian viruses such as the $\mathrm{H} 5 \mathrm{~N} 1$ and $\mathrm{H} 7 \mathrm{~N} 9$ that transmit from birds to humans [10,11]. The influenza viruses have threatened human health and life as well as continuously caused considerable damage on social and economic development [7,11]. Many people have recently been infected by a novel reassortant avian-origin influenza A virus (H7N9) having a death rate over 30\% [8,12]. The H9N2 avian influenza A virus is known to repeatedly infect humans and other mammals [13]. Hence, rapid and precise detection of influenza viruses at the early stage through immediate and accurate diagnostic techniques are required to prevent the occurrence of a serious influenza pandemic.

Various approaches are currently employed for diagnosing the viral infection, including virus isolation using cell culture, fluorescence immunoassay (FIA), enzyme-linked immunosorbent assay (ELIA), reverse transcriptase polymerase chain reaction (RT-PCR), and loop-mediated isothermal amplification (LAMP) [14-23]. The viral culture-based diagnostic approach is considered one of the gold standards for detecting a viral infection and subtyping the influenza virus. However, this method has a relatively long time-toresult duration (2-3 days), is a labor-intensive procedure, and requires well-trained personnel. Moreover, some viruses are difficult or even unable to cultivate in cell culture [17,24]. In addition, nucleic acid-based tests, especially RT-PCR, are commonly used for surveillance of influenza infection. Real-time RT-PCR assay has a high sensitivity and specificity [25]. However, its limitations include a relatively long detection time $(\sim 2 \mathrm{~h})$, expensive instruments and reagents, 
and requirement of well-trained technicians. The development of fast PCR-based point-of-care test for diagnosis of influenza infection have circumvented the drawbacks of real-time RT-PCR, such as Alere ${ }^{\mathrm{TM}}$ influenza A \& B test (Alere, Waltham, USA) and Coba ${ }^{\circledR}$ Influenza A/B assay (Roche, Basel, Swiss). These tests detect the virus with a sample-to-result time of less than $50 \mathrm{~min}[17,26]$. However, they have some limitations on the use of RNA as target for detection of influenza viruses. The stability of reagents for the RNA amplification could result in false negatives. In addition, these tests require to prepare new primers due to the high mutation rate of influenza virus and resulting new viruses [27].

Various immune-based rapid diagnostic tests have been developed for rapid diagnosis of influenza infection, such as Directigen EZ Flu A and B (Becton Dicknson, Sparks, USA), Binax Now Influenza A/B antigen kit (Binax, Portland, USA), Genedia influenza Ag (Green Cross, Yongin, Korea), Humasis Influenza A/B antigen test (Humasis, Anyang, Korea), SD Bioline rapid influenza kit (Standard Diagnostics, Yongin, Korea), and Quidel QuickVue Test (Quidel, San Diego, USA). Most of these protocols have a time-to-result duration of 15 to $30 \mathrm{~min}$. However, the main drawbacks of these tests include low sensitivity and specificity [28-30].

Recent advances in diagnostics of influenza viruses have led to development of simple, rapid, and sensitive biosensors for detection of the virus, including surface plasmon resonance (SPR) biosensor, quartz crystal microbalance (QCM) biosensor, surface enhanced Raman scattering (SERS) spectroscopy, electrochemical biosensor, impedance biosensor, metal-enhanced fluorescence (MEF) biosensor and digital ELISA [31-38]. The biosensors use antibodies or aptamer as the capture probe, but compensate the drawbacks of conventional diagnostics by introducing sensitive detection methods. However, antigenic drift could create problems of recognizing HA by antibodies and aptamers, resulting in serious false results. Alternatively, the glycan-based biosensors developed are capable of identifying subtypes of a given influenza virus because the human and avian viruses bind to different glycans expressed on the host cell: Neu5Ac- $\alpha(2-6)-G a l$ for humans and Neu5Ac- $\alpha(2-3)-G a l$ for avian [39-42].

This article reviews the current research on the development of simple, rapid, sensitive, and specific biosensors for detecting influenza viruses.

\section{Conventional Methods}

\subsection{Viral culture-based assay}

The tube cell culture method introduced in the 1940s is a standard method to detect influenza viruses and identify the various subtypes. The method involves inoculation with infectious samples, propagation for 7-10 days, and final confirmation through specific antibody staining, hemadsorption, or immunofluorescence microscopy. To reduce the time of tube cell culture method, the shell vial cell culture (SVC) has been used since 1990s for detection and subtyping of influenza viruses [14,43]. This approach uses small 1-dram vials or shell vials for propagation of viruses in mammalian cell. The SVC method is capable of detecting viral infection in $24-48 \mathrm{~h}$ with higher sensitivity compared to the tube cell culture method [44].

\subsection{Polymerase chain reaction (PCR)-based assay}

Most diagnostic labs around the world routinely use the WHO-approved reverse transcriptase polymerase chain reaction (RT-PCR) assay for typing and subtyping of influenza viruses. Modified RT-PCR-based assays been also been developed to improve sensitivity and specificity, and to reduce the experimental cost and time of conventional RT-PCR.

The loop-mediated isothermal amplification (LAMP) assay is a rapid, accurate, and cost-effective approach compared to conventional RT-PCR. Unlike conventional RT-PCR, the LAMP assay amplifies the target virus gene under isothermal conditions in a simple equipment, such as a heating block or water bath $[45,46]$. The approach is based on autocycling strand displacement DNA synthesis using avian myeloblastosis virus reverse transcriptase and Bst DNA polymerase with a high strand displacement activity. The assay uses two inner primers and two outer primers to recognize the target gene region, and two loop primers increase the sensitivity of the assay. The final DNA product is detected either by agarose gel electrophoresis, by precipitation of magnesium pyrophosphate by-product released in solution during amplification, or by the color change under UV irradiation with an intercalating fluorescent dye. The LAMP method detects the human influenza A virus subtype $\mathrm{H} 1 \mathrm{~N} 1, \mathrm{H} 2 \mathrm{~N} 2$, and $\mathrm{H} 3 \mathrm{~N} 2$ from clinical samples with identical detection limit to conventional PCR method [47]. Furthermore, Kubo et al. reported the development of a one-step, real-time reverse transcriptionloop-mediated isothermal amplification (RT-LAMP) assay for rapid detection of pandemic influenza virus (H1N1) during the 2009 outbreak [18]. The RT-LAMP assay detects the H1N1 HA gene within $40 \mathrm{~min}$ in clinical samples extracted from nasopharyngeal swab specimens of Japanese and Vietnamese patients, and exhibits an identical detection limit to the currently used RT-PCR method. Compared to the RT-PCR method, the RT-LAMP assay targeting the pandemic influenza virus (H1N1) HA genes showed 97.8\% sensitivity and $100 \%$ specificity. In addition to human 
influenza virus, the RT-LAMP method has been successfully implemented for the detection of avian influenza viruses [19,21]. RT-LAMP assay detects the H5N1 highly pathogenic avian influenza (HPAI) virus with a 100 -fold higher sensitivity than the RT-PCR method [21]. Using RNA samples from dead crows infected by H5N1-HPAI, RT-LAMP exhibited two positive results while RT-PCR showed only one positive result. The avian influenza virus (H7N9) was also detected using RT-LAMP with a sensitivity of 42.47 copies/reaction [21]. The RT-LAMP method showed no cross-reactivity with other viruses in all reported cases [18,19,21,47].

A new diagnostic assay SAMBA (simple amplificationbased assay), based on isothermal amplification and visual detection on dipstick, has been developed for the detection of influenza virus $[48,49]$. The SAMBA assay detected the pandemic H1N1 virus in RNA samples extracted from nasal/throat swab specimens from 256 patients with $95.3 \%$ sensitivity and $99.4 \%$ specificity, as compared to the United Kingdom National Standard Method based on quantitative RT-PCR [48]. Furthermore, the same group developed the SAMBA Flu duplex test by integrating extraction, isothermal amplification and detection processes into an enclosed semi-automated system for point-of-care diagnosis of the influenza $\mathrm{A} / \mathrm{B}$ virus infection [49]. The SAMBA Flu test detected 95 and 85 copies of viral genomes for influenza $A$ and $\mathrm{B}$ viruses without cross-reactivity to other common respiratory pathogens. Using clinical samples extracted from 328 nasal/throat and nasopharyngeal swab specimens from the United Kingdom and Belgium, the SAMBA Flu test showed $100 \%$ sensitivity and $97.9 \%$ specificity for influenza A virus, and 100\% sensitivity and 100\% specificity for influenza B virus, when compared to the quantitative RT-PCR method.

Nucleic acid sequence-based amplification (NASBA) has developed as an alternative method to overcome limitations of the RT-PCR method, including the longer assay time and risk of contamination [50,51]. The NASBA approach relies on the simultaneous reaction of three enzymes: avian myeloblastosis virus reverse transcriptase, T7 RNA polymerase, and RNaseH. The final product can be detected by the electrochemiluminescence (ECL) method using a molecular beacon [52], which is a hairpin oligonucleotide labeled with a fluorescence reporter dye and a quencher. The NASBA tool has been successfully used for rapid detection of influenza viruses [53], and the assay has been efficacious in detecting the influenza $\mathrm{A}$ virus in clinical samples obtained from patients during the 2003-2004 influenza outbreak [53]. The assay shows high sensitivity and specificity, detecting $0.1<$ TCID50 (median tissue culture infective dose) of virus stock and has identified more positive samples $(66 / 103)$ than detected in virus culturebased assay and immunofluorescence. In addition, the
NASBA assay has been applied to detect the novel swine origin influenza A virus (S-OIV) (H1N1) [54]. The assay has a detection limit of approximately 50 copies/ reaction, and exhibits sensitivity and specificity of $100 \%$ compared to viral culture, conventional RT-PCR, and real-time RTPCR. Furthermore, the modified NASBA assay, a simple method for amplifying RNA targets (SMART), minimizes the current limitations of the primary NASBA approach [55]. The single-stranded DNA (ssDNA) of the SMART method functions as a reporter molecule for capturing and separating viral RNA, and not as a primer as used in the RT-PCR and NASBA methods. The introduction of a microfluidic separation step in the SMART approach enables the separation of the target viral RNA from the sample mixture. The SMART amplification and detection steps depend on the complement to the ssDNA probe that anneals to the viral RNA rather than the viral RNA itself. The SMART approach is used for detecting and identifying subtypes of influenza viruses, pandemic H1N1, seasonal $\mathrm{H} 1 \mathrm{~N} 1$, and seasonal H3N2 [55]. Using 116 clinical nasopharyngeal swab samples, SMART showed a limit of detection (LOD) of $\sim 10^{5}$ RNA copies/mL with a time-topositivity (TTP) value of $70 \mathrm{~min}$. The approach also exhibited accurate detection in $98.3 \%$ samples, with a subtyping accuracy of $95.7 \%$.

\subsection{Serological assay}

Serological assay is a method commonly used to detect virus-specific antibodies in clinical samples. They include the hemagglutination inhibition (HI) assay, virus neutralization (VN) assay, single radial hemolysis (SRH), complement fixation assay, and enzyme-linked immunoabsorbant assay (ELISA) [16,56]. These assays are far less sensitive compared to the nucleic acid-based assays. For example, europium nanoparticle-based immunoassay showed sensitivities of $90.7 \%$ for influenza A viruses and $81.80 \%$ for influenza B viruses compared to those for RT-PCR assay in influenzapositive clinical samples [16].

\subsection{Rapid diagnostic kits}

Rapid influenza diagnostic tests are immune-based kits for detecting the viral nucleoprotein. Due to their ease of use, laboratory independence and fast turnaround time (10$30 \mathrm{~min}$ ), they are commonly used as point-of-care tests in diagnosing influenza infections. The rapid influenza diagnostic kits were compared to real-time RT-PCR for evaluating their performance $[28,29,57,58]$. Of the 144 clinical samples infected by pandemic influenza A virus (H1N1), the BinaxNOW assay could detect only $11.1 \%$ positive samples by RT-PCR [58]. For seasonal influenza 2007-08 and 2008-09, the BinaxNOW assay showed sensitivity of $37.5-51.9 \%$ as compared to the RT-PCR assay 
Table 1. Comparison of conventional methods for detection of influenza viruses

\begin{tabular}{|c|c|c|}
\hline Diagnostic methods & Advantages & Disadvantages \\
\hline Viral culture-based assay & $\begin{array}{l}\text { - Suitable for virus subtyping, recovery of novel } \\
\text { and divergent strains, and detection of } \\
\text { phenotypic resistance to antivirals }\end{array}$ & $\begin{array}{l}\text { - Less sensitive than PCR-based assay } \\
\text { - Relatively long detection time } \\
\text { - Unavailable for immediate patient care }\end{array}$ \\
\hline PCR-based assay & $\begin{array}{l}\text { - High sensitivity and specificity } \\
\text { - Suitable for distinguishing influenza types and } \\
\text { subtypes, and detecting genotypic resistance }\end{array}$ & $\begin{array}{l}\text { - High cost and technical demands } \\
\text { - Unavailable for distinguishing non-viable from } \\
\text { viable viruses }\end{array}$ \\
\hline Serological assay & $\begin{array}{l}\text { - Suitable for detection of influenza virus when } \\
\text { specimens were collected too late }\end{array}$ & $\begin{array}{l}\text { - Requirement of paired serum patients } \\
\text { - Unavailable for immediate patient care }\end{array}$ \\
\hline Rapid diagnostic kit & $\begin{array}{l}\text { - Fast } \\
\text { - Simple test without technical expertise and } \\
\text { infrastructure }\end{array}$ & $\begin{array}{l}\text { - Low sensitivity } \\
\text { - Unavailable for distinguishing influenza A subtype }\end{array}$ \\
\hline
\end{tabular}

[59]. In addition, the Daum group evaluated five FDAapproved rapid influenza diagnostic kits for the pandemic influenza virus H1N1: Becton Dickinson Directigen EZ Flu A+B, 3M Rapid Detection Flu A+B Test, BinaxNOW Influenza $A \& B$, Quidel QuickVue Influenza $A+B$, and Remel X/pect Flue A\&B [28]. All kits had low sensitivity of $16-18 \%$ when compared to RT-PCR, at a viral concentration of $<10^{2}$ TCID50/mL. In addition to the pandemic influenza virus H1N1, Cho et al. evaluated the five rapid diagnostic kits (Directizen EZ Flu A and B, Binax Now Influenza A/B antigen kit, Genedia influenza Ag, Humasis Influenza A/B antigen test and SD Bioline rapid influenza kit) using clinical samples collected from patients presenting with influenzalike symptoms between 2009 to 2011 in South Korea [29]. Their results also showed relatively high sensitivity of 71-82.1\% for influenza A while exhibiting low sensitivity of $37.2-47.7 \%$ for influenza B.

General advantages and disadvantages of conventional methods for identification of influenza viruses were summarized in Table 1.

\section{Biosensors}

\subsection{Electrochemical biosensor}

Electrochemical biosensors have been used for detection of influenza virus due to their rapid, practical, sensitive, and economical properties as compared to conventional techniques. Several factors have been considered in developing electrochemical biosensors for detecting influenza viruses: selection of electrode material, electrochemical method, detection probe to be used for detecting the target, and effective signal amplifier. The developed electrochemical biosensors are summarized in Table 2. The electrochemical DNA biosensor was developed for detection of the avian influenza virus (H5N1) [60]. The biosensor was fabricated by immobilizing two different oligonucleotide probes on a gold electrode via $\mathrm{Au}-\mathrm{S}$ formation. One of the probes is a single-stranded DNA (ssDNA) bound to ferrocene on its 5'-end (ssDNA-Fc), which is complementary to the complementary DNA (cDNA) encoding a part of H5 HA of the H5N1 virus. The second probe is a ssDNA bound to methylene blue on its 5'-end (ssDNA-MB), which is complementary to the cDNA encoding a part of N1 neuraminidase from the same virus. All measurements were carried out by using the Osteryoung square-wave voltammetry (SWV). The signal was obtained through the dual signal mode: "signal on" mode by ssDNA-Fc and "signal off" mode by ssDNA-MB. The biosensor showed a LOD of 18-21 nM for both targets with good selectivity. In addition to ssDNA, DNA tetrahedral probe was used as detection probe to develop electrochemical biosensors for the detection of the avian influenza virus (H7N9) [61]. As a detection probe, the DNA tetrahedral nanostructure contributes to precise control of the biomolecule-confined surface in the biosensor, resulting in enhanced molecular recognition and high reproductivity [62,63]. The DNA tetrahedral probe was immobilized onto a gold electrode through self-assembly of three thiolated nucleotide sequences and a longer nucleotide sequence containing DNA complementary to the target ssDNA. The target ssDNA was obtained by asymmetric PCR of the cDNA from the viral lysate of H7N9 in throat swabs. The signal was obtained by the enzymatic reaction of horseradish peroxidase conjugated on the ssDNA detection probe. Cyclic voltammetry (CV), electrochemical impedance spectroscopy (EIS), and amperometric mode evaluated all measurements in this study. The electrochemical biosensor exhibited an LOD of $100 \mathrm{fM}$ for target sequence. The biosensor shows a high selectivity, specifically recognizing the target DNA even from single-mismatched oligonucleotides.

Malecka et al. proposed an exploitation of the redoxactive monolayer on gold electrode in an electrochemical DNA (or RNA) biosensor for detection of H5N1 [64]. The redox active layer has an advantage on signal generation since the layer converts intermolecular recognition processes 
Table 2. A comparison of electrochemical biosensors for detection of influenza virus

\begin{tabular}{|c|c|c|c|c|c|c|}
\hline $\begin{array}{l}\text { Electrode } \\
\text { materials }\end{array}$ & $\begin{array}{c}\text { Biological } \\
\text { capture probe }\end{array}$ & Analytes & Electrochemical method & LOD & $\begin{array}{l}\text { Detection } \\
\text { time }\end{array}$ & Reference \\
\hline $\mathrm{Au}$ & Oligonucleotide & cDNA of H5N1 virus & SWV & $18-21 \mathrm{nM}$ & - & 60 \\
\hline $\mathrm{Au}$ & Oligonucleotide & cDNA of H7N9 virus & CV, EIS, Amperometric & $100 \mathrm{fM}$ & - & 61 \\
\hline $\mathrm{Au}$ & Oligonucleotide & $\begin{array}{l}\text { DNA and RNA of } \\
\text { H5N1 virus }\end{array}$ & CV, SWV, DPV & $\begin{array}{l}0.87 \mathrm{pM} \text { for DNA } \\
73 \mathrm{pM} \text { for RNA }\end{array}$ & - & 64 \\
\hline $\mathrm{Pt}$ & Oligonucleotide & DNA of $\mathrm{H} 1 \mathrm{~N} 1$ virus & LSV & $8.4 \mathrm{pM}$ & - & 65 \\
\hline $\mathrm{Au}$ & Aptamer & $\mathrm{H} 5 \mathrm{~N} 1$ virus & EIS & $8 \times 10^{-4} \mathrm{HA}$ in $200 \mu \mathrm{L}$ & - & 67 \\
\hline $\mathrm{Au}$ & Glycan & $\mathrm{H} 3 \mathrm{~N} 2$ virus & EIS & 13 viral particles & - & 70 \\
\hline $\mathrm{Au}$ & Glycan & H9N2 virus & EIS & $10^{-8} \mathrm{U} / \mathrm{mL}$ & - & 72 \\
\hline $\mathrm{Au}$ & Glycan & Human influenza $\mathrm{A}$ virus & Amperometric & $0.025 \mathrm{HAU}$ & - & 40 \\
\hline $\mathrm{Hg}$ & Glycan & $\mathrm{H} 5 \mathrm{~N} 1$ virus & CV, DPV & - & - & 42 \\
\hline- & Glycan & $\mathrm{H} 1 \mathrm{~N} 1$ and $\mathrm{H} 3 \mathrm{~N} 2$ viruses & Amperometric & $10^{2} \mathrm{PFU}$ & $15 \mathrm{~min}$ & 41 \\
\hline $\mathrm{Au}$ & Antibody & $\mathrm{H} 5 \mathrm{~N} 1$ virus & EIS & $2^{-1} \mathrm{HAU} / 50 \mu \mathrm{L}$ & $1 \mathrm{~h}$ & 36 \\
\hline Diamond & Antibody & M1 protein & EIS & $1 \mathrm{fg} / \mathrm{mL}$ & $5 \mathrm{~min}$ & 34 \\
\hline $\mathrm{Pt}$ & Antibody & H7N9 virus & LSV & $7.8 \mathrm{fg} / \mathrm{mL}$ & - & 31 \\
\hline $\mathrm{C}$ & Antibody & H9N2 virus & $\mathrm{CV}$, chronoamperometry & $16 \mathrm{HAU}$ & - & 78 \\
\hline $\mathrm{C}$ & Antibody & $\mathrm{H} 5 \mathrm{~N} 1$ virus & EIS & $2.1 \mathrm{pg} / \mathrm{mL}$ & - & 79 \\
\hline
\end{tabular}

to analytically detectable ones without external redox active markers. The biosensor was developed by immobilizing $\mathrm{NH}_{2}$-functionalized ssDNA (20-mer) onto epoxy groups of phen-epoxy-Fe(III)-(phen-epoxy) $)_{2}$ redox layer on a gold electrode. The signal was measured through CV, SWV, and differential pulse voltammetry (DPV). The biosensor exhibited an LOD of 0.87 and $73 \mathrm{pM}$ for the target molecules 20-mer DNA and 280-mer RNA, respectively. In addition, Lee et al. developed DNA-functionalized gold/iron-oxide nanoparticle-carbon nanotube (CNT) hybrid materials to enhance the sensitivity of the electrochemical biosensor for detection of the H1N1 virus [65]. Nanoparticle-functionalized carbon nanomaterials have excellent electrical conductivity [66]. The electrochemical biosensor was fabricated by magnetically aligning gold/iron oxide magnetic particles (MP)-CNT followed by an immobilization of thiol groupfunctionalized DNA probe. The signal was obtained using linear sweep voltammetry (LSV). The biosensor exhibited a LOD of $8.4 \mathrm{pM}$ while showing high selectivity against different DNA diseases.

Enzyme catalysis was exploited in ultra-low ion strength media to increase the ionic strength to enable developing an impedance detection method in an electrochemical aptamer biosensor [67]. The ultra-low ion strength media circumvents the limitation of media with high ion concentration, including a high background in electrochemistry. For the target gene-capturing particles, H5N1-specific aptamerfunctionalized magnetic beads were fabricated by incubating the biotin-labeled aptamer with streptavidin-coated magnetic beads. For the signal-generating particles, concanavalin A
(ConA)/glucose oxidase (GOx)/Au nanoparticles (AuNPs) bionanocomposite were prepared through noncovalent interaction. The sandwich complex formed in presence of H5N1 was transferred to glucose solution, and the signal was measured on screen-printed interdigitated array electrodes using EIS. The biosensor showed a detection limit of $8 \times 10^{-4}$ HA activity unit (HAU) in $200 \mu \mathrm{L}$.

Glycan-based electrochemical biosensors have been developed for the detection of influenza viruses and identification of the various subtypes. Glycans have received significant attention as detection probes as they are natural receptors since influenza viruses and its subtypes have different glycan-binding specificities [68,69]. Hushegyi et al. developed glycan-based impedimetric biosensors for ultrasensitive detection of the influenza virus [70]. Previously, they developed glycan-based impedimetric biosensors by immobilizing the amino-terminated $\alpha 2,3$-siallylactose onto gold electrode coated by carboxyl group-functionalized selfassembled monolayer consisting of 11-mercaptoundecanoic acid and 6-mercaptohexanol [71]. The biosensor detected HAs from avian influenza viruses (H5N1) at the attomolar level. To increase selectivity of detection in glycan-based impedimetric biosensors, gold electrodes coated on a selfassembled monolayer (SAM) composed of oligoethylene glycol moieties were used [70]. The biosensor was fabricated by immobilizing amino-terminated $\alpha 2,3$-siallylactose onto the carboxyl group-functionalized gold electrode. While the glycan biosensor selectively detected the influenza $\mathrm{H} 3 \mathrm{~N} 2$ over the H7N7 control with a selectivity ratio of 30 , the biosensor exhibited an LOD of $13 \mathrm{H} 3 \mathrm{~N} 2$ viral particles 
in $1 \mu \mathrm{L}$ solution. Further, an electrochemical glycan biosensor based on Au-screen printed electrode modified by grapheneAu hybrid nanocomposite was developed for the detection of influenza virus [72]. The glycan source was obtained by using fetuin A, a glycoprotein with 12-14 terminal sialic acid residues per molecule. The biosensor used the property of detection of neuraminidase activity through peanut agglutinin lectin being capable of monitoring the cleavage of sialic acid. All measurements were carried out by EIS. The biosensor showed an LOD of $10^{-8} \mathrm{U} / \mathrm{mL}$ with a linear range of $10^{-8} \mathrm{U} / \mathrm{mL}$ and $10^{-1} \mathrm{U} / \mathrm{mL}$. The biosensor also showed a potential application for detecting the influenza virus (H9N2) propagated in chicken eggs. In addition to gold electrode, organic electrochemical transistor (OECT) with $\alpha 2,6$-siallylacotose-grafted conductive polymer channel was used to develop electrochemical biosensor for detecting the human influenza A virus [40]. For potentiometric sensing, 3,4-ethylenedioxythiophene (EDOT) and its adduct bearing an oxylamine group (EDOTOA) were copolymerized on OECT channel composed of poly(3,4-ethylenedioxythiophene): poly(styrenesulfonate) (PEDOT:PSS). The signal was obtained by using an amperometric mode. The LOD of biosensor was more than two orders of magnitude when compared to the commercial immunochromatographic assay over the same detection time.

Microfluidic chip based on $\alpha 2,6$-sialyllactosaminefunctionalized 3-dimensional MPs was developed for the detection of influenza virus H5N1 [42]. The glycanfunctionalized MPs were fabricated by immobilizing biotinylated $\alpha 2,6$-sialyllactosamine onto streptavidin-modified MPs. To isolate and detect the influenza virus, vaccine HA (influenza vaccine Vaxigrip ${ }^{\circledR}$ ) labeled with $\mathrm{CdS}$ quantum dots (QDs) were used. All measurements were obtained by using CV and DPV. Under optimized conditions of glycan concentration, reaction temperature, and reaction time, the biosensor exhibited an accuracy of detection method higher than $80 \%$ for detection of CdS-labeled HA. Also, the biosensor could selectively detect inactivated H5N1 over two negative controls.

Electrochemical glycan biosensor based on glucose test strips and a handheld potentiostat was developed for rapid and precise detection of influenza viruses at point-of-care settings [41]. The working principle is based on the amperometric detection of galactose released from 4,7-diOMe $\mathrm{N}$-acetylneuraminic acid- $\alpha 2,3$ (or 2,6)-galactose by the influenza virus NA, using a handheld potentiostat and dehydrogenase-bearing glucose test strips. The biosensor exhibited a LOD of $10^{2} \mathrm{PFU}$ (plaque forming unit) per sample for H1N1 A/Brisbane/59/2007 and H3N2 A/Victoria/361/2011, with a short reaction time of $15 \mathrm{~min}$. Also, the biosensor showed high specificity for the influenza virus over Streptococcus pneumonia and Haemophilus influenza.
Electrochemical immunosensors are commonly used for the detection of influenza virus. Recently, an impedance immunosensor based on low-cost microelectrodes and specific monoclonal antibodies was developed for rapid detection of the avian influenza virus $\mathrm{H} 5 \mathrm{~N} 1$ in chicken swab [36]. The low-cost gold microelectrode was fabricated by improved wet-etching fabrication and not the commonly used costly dry-etching method. The specific monoclonal antibodies with good affinity and specificity for the H5N1 virus were obtained by fusion of mouse myeloma cells with spleen cells isolated from an H5N1 virus-immunized mouse. The antibodies were immobilized on Protein Amodified microelectrode. The biosensor showed a LOD of $2^{-1} \mathrm{HAU} / 50 \mu \mathrm{L}$ with no cross-reactivity over non-target viruses such as H6N2, H9N2, Newcastle disease virus (NDV), and infectious bronchitis virus. The biosensor also exhibited an accuracy of $\sim 90 \%$ in chicken swab testing using viral isolates, which is comparable with real-time RTPCR. In addition, an impedance immunosensor based on boron-doped diamond (BDD) electrode was developed for rapid-response ultrasensitive detection of the influenza virus [34]. The BDD electrode has remarkable electrochemical properties such as low background current, wide potential window, high stability, chemical inertness, and fast electrochemical response [73-75]. The anti-matrix protein 1 (M1) protein antibodies are used and immobilized onto 4aminobenzoic acid self-assembled layer on a BDD surface. The biosensor exhibited a LOD of $1 \mathrm{fg} / \mathrm{mL}$ in saliva buffer for the M1 protein within $5 \mathrm{~min}$, which corresponds to 5-10 viruses per sample.

Digital single virus electrochemical enzyme-linked immunoassay (Digital ELISA) was developed for the ultrasensitive counting of avian influenza virus H7N9 [31]. For this purpose, the digital ELISA was integrated by digital analysis, bifunctional fluorescence magnetic nanospheres (bi-FMNs), and monolayer AuNPs-modified microelectrode array (MA). The digital analysis enables the virus to be detected at low concentration signals of " 0 " or " 1 ", regardless of the concrete strength of signals [76,77]. The bi-FMNs were fabricated by co-immobilizing polyclonal anti-H7N9 HA antibody and alkaline phosphatase. The monoclonal anti-H7N9 HA antibodies were immobilized onto monolayer AuNPs-modified MA. The electrochemical signal was obtained by using LSV and converted into digital signal. The digital analysis-integrated ELISA exhibited an LOD of $7.8 \mathrm{fg} / \mathrm{mL}$ for H7N9 virus.

Contrary to previously reported electrochemical immunosensors, the electrochemical detection of influenza virus H9N2 was performed using antibody immobilization on electrode-free sensor platform based on both immunomagnetic extraction and gold catalysis [78]. The virus H9N2 was isolated from the allantoic fluid by using anti-M2 
protein antibody-functionalized iron magnetic nanoparticles (MNPs), followed by the formation of the MNP-H9N2AuNP complex using fetuin A-coated AuNPs. The complex was isolated and the collected AuNPs by acid treatment were deposited on a screen printed carbon electrode. All measurements were carried out using $\mathrm{CV}$ and chronoamperometry. The biosensor detected the virus H9N2 at a titer less than 16 HAU. In addition to viral antigens, an electrochemical immunosensor was developed for the detection of antibodies against influenza A virus $\mathrm{H} 5 \mathrm{~N} 1$ in hen serum [79]. The biosensor was prepared by successively immobilizing anti-His $\operatorname{IgG}$ monoclonal antibody and recombinant His-tagged HA on Protein A-functionalized glassy carbon electrode. Two variants of the short and long recombinant $\mathrm{HA}$ from avian influenza virus $\mathrm{H} 5 \mathrm{~N} 1$ were used as the target HA. The anti-H5 HA monoclonal antibody was used as the model antibody. The interaction between $\mathrm{HA}$ and anti-H5 antibody was measured by EIS. The biosensor exhibited an LOD of $2.1 \mathrm{pg} / \mathrm{mL}$ and a quantification limit of $6.3 \mathrm{pg} / \mathrm{mL}$, with a dynamic range from $4 \mathrm{pg} / \mathrm{mL}$ to $20 \mathrm{pg} / \mathrm{mL}$. The biosensor also detected antibodies in hen serum diluted up to $7 \times 10^{7}$-fold, which corresponds to about four orders of magnitude better than conventional ELISA.

\subsection{Optical biosensor}

Lateral flow assay (LFA)-based biosensors have been commercialized for the diagnosis of influenza virus since they are able to perform point-of-care by a simple method without expensive specialized tools and diagnose target diseases in a short time. The dual recognition element LFA (DRELFA) biosensor was developed for simple, rapid, sensitive, and specific detection of particular influenza virus [80]. The DRELFA uses two recognition probes, a nucleic acid aptamer and an antibody, to overcome the individual limitations of antibodies and aptamers, including cross-reactivity and slow binding kinetics. For the detection of A/Panama/2007/99 strain (H3N2), a Panama/99-specific RNA aptamer having a biotin at its 5'-end and anti-H3 antibody conjugated with $37 \mathrm{~nm}$ AuNPs were used. The combination contributed to improved specificity of the DRELFA compared to the currently available antibodybased LFA systems for the A/Panama/2007/99 strain of H3N2 virus over other H3N2 strains. Over $90 \%$ of the analyte was localized to the test line in the DRELFA. The DRELFA showed high sensitivity of detecting the influenza virus in 50-fold diluted sample, equivalent to $2 \times 10^{6}$ virus particles. The signal of DRELFA also correlated well with quantitative RT-PCR results. To capture the probe, various signal amplification strategies have been reported for sensitive and early detection of the influenza A virus on LFA [81,82]. Park et al. developed surface-enhanced Raman scattering (SERS)-based LFA in which the commonly used gold nanoparticle in LFA was replaced with SERS-active nano tags [81]. The SERS-active nanotag was conjugated with polyclonal anti-influenza A virus (A/H1N1pdm/Korea/ 2785/2009). The biosensor exhibited an LOD of $1.9 \times 10^{4}$ $\mathrm{PFU} / \mathrm{mL}$, which is approximately one order of magnitude more sensitive than the LOD measured by using the colorimetric LFA. Furthermore, a carbon nanotag-based LFA was developed for the detection of influenza virus [82]. The carbon nanotag was labelled on anti-influenza A virus nucleoprotein antibody. The LFA detected the influenza A virus (A/Thailand/104/2009 (H1N1)) from allantoic acid with a LOD of $350 \mathrm{TCID}_{50} / \mathrm{mL}$. No reaction was observed with uninfected MDCK cells, and there was no cross-reaction with human serum albumin, lysozyme, dopamine, glucose and influenza virus B.

A novel colorimetric assay based on enzyme-induced metallization coupled with immunomagnetic separation was developed for highly sensitive detection of avian influenza virus H9N2 [83]. This principle of colorimetric assay measures the color change through the deposition of silver on AuNPs induced by alkaline phosphatase (ALP). Monoclonal anti-H9N2 HA antibody-functionalized magnetic beads (IMBs) were prepared through EDC/NHS chemistry and used to isolate the target H9N2 virus from samples. Biotinylated polyclonal anti-H9N2 antibody (pAb) was used to introduce streptavidin-labeled ALP into the IMBs/ H9N2 complex. IMBs/H9N2/pAb/ALP composites were detected through a color change in detection solution containing $p$-aminophenyl phosphate, $\mathrm{AgNO}_{3}$, and AuNPs. The biosensor exhibits an LOD of $17.5 \mathrm{pg} / \mathrm{mL}$ H9N2 virus with high specificity over H5N1, H1N1, and NDV, with a detection time of about $1.5 \mathrm{~h}$. In addition, a colorimetric immunoassay based on peroxidase-like activity of Au-CNT nanohybrids was developed for detecting the influenza virus A/Yokohama/110/2009 (H3N2) [84]. Anti-H3N2 antibodies were conjugated to Au-CNT nanohybrids through EDC/NHS chemistry. The sensor showed an LOD of 3.4 PFU/mL H3N2 in human serum, which is 385 times lower than that of conventional ELISA (1312 PFU $/ \mathrm{mL}$ ). The sensitivity was also 500 times greater than that of commercial immunochromatography kits. Furthermore, horseradish peroxidase (HRP)-encapsulated liposome was applied for the development of colorimetric immunosensor for detection of influenza virus $\mathrm{H} 5 \mathrm{~N} 1$ [85]. H5N1 was detected by interacting with the capture antibody and the biotinylated detection antibody, followed by the addition of biotin-tagged liposome encapsulated with HRP and substrates (3,3',5,5'-tetramethylbenzidine (TMB) and $\mathrm{H}_{2} \mathrm{O}_{2}$ ). The sensor exhibited an LOD of $0.04 \mathrm{ng} / \mathrm{mL}$, which is much higher than conventional ELISA.

In addition to antibodies, aptamer was used as a capture probe in the development of colorimetric biosensors for the 
rapid detection of influenza viruses [86]. The RNA aptamer for HA of influenza virus B/Johannesburg/05/1999 (J1999V) was conjugated with $5 \mathrm{~nm}$ AuNPs. In the presence of J1999V, the virus interacted with the AuNP-conjugated aptamers, forming a gold nanoshell (AuNS) around the viral envelope. The purified AuNS was detected by naked eyes or UV-Vis spectra. This assay detected $3 \times 10^{8}$ viral particles.

Surface plasmon resonance (SPR) technique was used for the detection of influenza viruses because it is a labelfree and real-time technique with the added benefits of easy operation and setup $[32,87,88]$. Loo et al. developed a non-PCR MARS (MicroRNA-RNase-SPR) assay using ribonuclease $\mathrm{H}$ (RNase $\mathrm{H}$ ) and SPR to detect the microRNA miR-29a-3p from human subjects infected with the influenza virus H1N1 [87]. The cDNA for the mature miRNA Homo sapiens (hsa) was prepared from reverse transcription using stem-loop primers. The biotinylated RNA probe for the cDNA was immobilized on SRP surface through thiolinkage. The RNA probe-immobilized SPR surface was successively treated with the cDNA and RNase $\mathrm{H}$ to generate the change of SPR signal. The MARS showed an LOD of $1 \mathrm{nM}$ for the miR-29a-3p and detected the target gene within 1 hour without thermal cycling. Furthermore, the single nucleotide polymorphisms of $\mathrm{H1}$ gene in influenza virus was detected using the SPR technique and chimeric DNA oligomer containing neutral nucleotides with a methylated phosphate group [88]. In addition, Chang et al. developed an intensity-modulated SPR (IM-SPR) biosensor integrated with a new generated monoclonal antibody for rapid and sensitive detection of an avian influenza virus A (H7N9) [32]. The sensor showed an LOD of 144 copies/mL for H7N9 virus, which is a twenty-fold higher than that of conventional ELISA using an identical antibody. For spiked clinical specimens containing the H7N9 virus mixed with nasal mucosa from flu-like syndrome patients, the sensor exhibited an LOD of 402 copies $/ \mathrm{mL}$, which is better than quantitative RT-PCR and RIDT. Importantly, the sensor could detect the target virus within $10 \mathrm{~min}$. The developed optical biosensors are summarized in Table 3.

\subsection{Mass-based biosensor}

Quartz crystal microbalance (QCM) biosensors have received significant attention in applications for detecting influenza viruses because of their advantages of costeffectiveness, simplicity, direct detection, and real-time output $[38,89,90]$. Wang et al. developed a hydrogel based QCM aptasensor for detection of avian influenza virus (H5N1) [89]. An aptamer with high affinity and selectivity for surface protein of $\mathrm{H} 5 \mathrm{~N} 1$ virus was used as the capture probe. The hydrogel was prepared through the crosslinking between the aptamer and single-stranded DNA (ssDNA) in polyacrylamide network and immobilized onto gold surface of a QCM sensor. H5N1 virus was detected by measuring the change in frequency depending on the dissolution between the aptamer and ssDNA in the presence of H5N1

Table 3. A comparison of optical biosensors for detection of influenza virus

\begin{tabular}{|c|c|c|c|c|c|c|}
\hline Sensor type & $\begin{array}{l}\text { Biological } \\
\text { capture probe }\end{array}$ & Analyte & Detection method & LOD & $\begin{array}{l}\text { Detection } \\
\text { time }\end{array}$ & Reference \\
\hline LFA & $\begin{array}{l}\text { Nucleic acid } \\
\text { aptamers and } \\
\text { Antibody }\end{array}$ & $\mathrm{H} 3 \mathrm{~N} 2$ virus & $\begin{array}{l}\text { Naked eye observation } \\
\& \text { color intensity }\end{array}$ & $2 \times 10^{6}$ virus particles & $15 \mathrm{~min}$ & 80 \\
\hline LFA & Antibody & $\mathrm{H} 1 \mathrm{~N} 1$ virus & $\begin{array}{l}\text { Surface enhanced Raman } \\
\text { scattering spectroscopy }\end{array}$ & $1.9 \times 10^{4} \mathrm{PFU} / \mathrm{mL}$ & $<30 \min$ & 81 \\
\hline LFA & Antibody & H1N1 virus & $\begin{array}{l}\text { Naked eye observation } \\
\& \text { color intensity }\end{array}$ & $350 \mathrm{TCID}_{50} / \mathrm{mL}$ & $15 \mathrm{~min}$ & 82 \\
\hline $\begin{array}{l}\text { Biometallization- } \\
\text { based assay }\end{array}$ & Antibody & H9N2 virus & $\begin{array}{l}\text { Naked eye observation } \\
\& \text { absorbance }\end{array}$ & $17.5 \mathrm{pg} / \mathrm{mL}$ & $1.5 \mathrm{~h}$ & 83 \\
\hline $\begin{array}{l}\text { Gold-carbon } \\
\text { nanotube hybrid } \\
\text { assay }\end{array}$ & Antibody & $\mathrm{H} 3 \mathrm{~N} 2$ virus & $\begin{array}{l}\text { Naked eye observation } \\
\& \text { absorbance }\end{array}$ & 3.4 PFU/mL & $<4 \mathrm{~h}$ & 84 \\
\hline ELISA & Antibody & H5N1 virus & $\begin{array}{l}\text { Naked eye observation } \\
\& \text { absorbance }\end{array}$ & $0.04 \mathrm{ng} / \mathrm{mL}$ & $<7 \mathrm{~h}$ & 85 \\
\hline $\begin{array}{l}\text { Gold nanoshell } \\
\text { based assay }\end{array}$ & Aptamer & $\mathrm{H} 5 \mathrm{~N} 1$ virus & Naked eye observation & $3 \times 10^{8}$ virus particles & - & 86 \\
\hline SPR & MicroRNA & H1N1 virus & SPR signal intensity & $1 \mathrm{nM}$ & $1 \mathrm{~h}$ & 87 \\
\hline SPR & $\begin{array}{l}\text { Neutralized } \\
\text { chimeric DNA }\end{array}$ & H1 DNA & SPR signal intensity & - & - & 88 \\
\hline SPR & Antibody & H7N9 & SPR signal intensity & 402 copies/mL & $10 \mathrm{~min}$ & 32 \\
\hline
\end{tabular}


Table 4. A comparison of mass-based biosensors for detection of influenza virus

\begin{tabular}{|c|c|c|c|c|c|c|}
\hline $\begin{array}{l}\text { Sensor } \\
\text { type }\end{array}$ & $\begin{array}{c}\text { Biological } \\
\text { capture probe }\end{array}$ & Analyte & Detection method & LOD & $\begin{array}{l}\text { Detection } \\
\text { time }\end{array}$ & Reference \\
\hline QCM & Aptamer & H5N1 & QCM signal intensity & $0.0128 \mathrm{HAU}$ & $30 \mathrm{~min}$ & 89 \\
\hline QCM & Aptamer & $\mathrm{H} 5 \mathrm{~N} 1$ & QCM signal intensity & $2^{-4} \mathrm{HAU} / 50 \mu \mathrm{L}$ & $10 \mathrm{~min}$ & 38 \\
\hline QCM & Glycan & $\mathrm{H} 5 \mathrm{~N} 3, \mathrm{H} 5 \mathrm{~N} 1, \mathrm{H} 1 \mathrm{~N} 3$ & QCM signal intensity & - & - & 90 \\
\hline
\end{tabular}

Table 5. A comparison of biosensors for detection of influenza virus

\begin{tabular}{lll}
\hline Type of biosensor & \multicolumn{1}{c}{ Advantages } & \multicolumn{1}{c}{ Disadvantages } \\
\hline Electrochemical biosensors & $\bullet$ Real-time detection & $\bullet$ Bulky equipment \\
& $\bullet$ High sensitivity & $\bullet$ Sensitive to sample matrix \\
& $\bullet$ Relatively short detection time & $\bullet$ Not suitable for point-of-care \\
Optical biosensors & $\bullet$ Need of trained specialists \\
& $\bullet$ Real-time detection & $\bullet$ Bulky equipment \\
& $\bullet$ High throughput & $\bullet$ Sensitive to sample matrix \\
Mass-based biosensors & $\bullet$ Relatively short detection time & $\bullet$ Not suitable for point-of-care \\
& $\bullet$ Real-time detection & $\bullet$ Need of trained specialists \\
& $\bullet$ High sensitivity & $\bullet$ Bulky equipment \\
& $\bullet$ Relatively short detection time & $\bullet$ Sensitive to sample matrix \\
& & $\bullet$ Not suitable for point-of-care \\
& & $\bullet$ Need of trained specialists
\end{tabular}

virus. The sensor showed high sensitivity with an LOD of $0.0128 \mathrm{HAU}$ and a detection time of $30 \mathrm{~min}$. Furthermore, Wang et al. applied a 3-dimensional nanowell onto the gold surface of a QCM sensor for detection of avian influenza virus (H5N1) [38]. A nanowell-based electrode was fabricated by immobilizing a nanoporous gold film onto the gold electrode. An H5N1-specifc ssDNA aptamer was used as a capture probe. A nanowell-based QCM aptasensor was prepared by immobilizing the aptamer onto the nanowellbase electrode. The sensor showed a sensitivity with an LOD of $2^{-4} \mathrm{HAU} / 50 \mu \mathrm{L}$ and a detection time of $10 \mathrm{~min}$. The sensor had a dramatically reduced detection time when compared to the hydrogel-based QCM aptasensor [89]. In addition to the aptamer as a capture probe, glycan was used to develop a QCM sensor for detection of influenza viruses. Wangchareansak et al. showed the possibility of a QCM sensor based on self-assembled glucosamine monolayer as a biomimetic receptor to detect influenza virus $\mathrm{H} 5 \mathrm{~N} 3$, H5N1, and H1N3 [90]. The developed mass-based biosensors are summarized in Table 4.

\section{Conclusion}

This review focuses on the current development in biosensors with high sensitivity and selectivity for effective detection of influenza viruses. Compared to conventional methods, the current biosensors exhibit high sensitivity and selectivity with reduced detection times. Currently, there are several limitations to the application of biosensors for practical detection of influenza viruses in real samples, including the need of trained specialists to conduct them and/or a lower accuracy. General pros and cons of biosensors for detecting influenza viruses were summarized in Table 5. Continuous developments in the biosensor platforms will help to overcome these limitations.

\section{Acknowledgement}

This work was supported by the 2015 Yeungnam University Research Grant (215A580068).

\section{References}

1. De Clercq, E. (2006) Antiviral agents active against influenza A viruses. Nat. Rev. Drug Discov. 5: 1015-1025.

2. Matrosovich, M. N., T. Y. Matrosovich, T. Gray, N. A. Roberts, and H. D. Klenk (2004) Neuraminidase is important for the initiation of influenza virus infection in human airway epithelium. J. Virol. 78: 12665-12667.

3. McBride, W. J. H. (2010) Mandell, Douglas, and Bennett's Principles and Practice of Infectious Diseases, 7th edition. Sex Health 7: 218-218.

4. Ohuchi, M., N. Asaoka, T. Sakai, and R. Ohuchi (2006) Roles of neuraminidase in the initial stage of influenza virus infection. Microbes Infect. 8: 1287-1293.

5. Wu, Y., Y. Wu, B. Tefsen, Y. Shi, and G. F. Gao (2014) Batderived influenza-like viruses $\mathrm{H} 17 \mathrm{~N} 10$ and H18N11. Trends Microbiol. 22: 183-191.

6. Palese, P. (2004) Influenza: old and new threats. Nat. Med. 10: S82-S87. 
7. Beigel, H., H. Farrar, A. M. Han, F. G. Hayden, R. Hyer, M. D. de Jong, S. Lochindarat, N. T. K. Tien, N. T. Hien, T. T. Hien, A. Nicoll, S. Touch, K. Y. Yuen, and W. C. H. Influenza (2005) Current concepts - Avian influenza A (H5N1) infection in humans. New Engl. J. Med. 353: 1374-1385.

8. Gao, R. B., B. Cao, Y. W. Hu, Z. J. Feng, D. Y. Wang, W. F. Hu, J. Chen, Z. J. Jie, H. B. Qiu, K. Xu, X. W. Xu, H. Z. Lu, W. F. Zhu, Z. C. Gao, N. J. Xiang, Y. Z. Shen, Z. B. He, Y. Gu, Z. Y. Zhang, Y. Yang, X. Zhao, L. Zhou, X. D. Li, S. M. Zou, Y. Zhang, X. Y. Li, L. Yang, J. F. Guo, J. Dong, Q. Li, L. B. Dong, Y. Zhu, T. Bai, S. W. Wang, P. Hao, W. Z. Yang, Y. P. Zhang, J. Han, H. J. Yu, D. X. Li, G. F. Gao, G. Z. Wu, Y. Wang, Z. H. Yuan, and Y. L. Shu (2013) Human infection with a novel avian-origin influenza A (H7N9) virus. New Engl. J. Med. 368: 1888-1897.

9. Park, J. K. and J. K. Taubenberger (2016) Universal influenza vaccines: To dream the possible dream? ACS Infect. Dis. 2: 5-7.

10. Peaper, D. R. and M. L. Landry (2014) Rapid diagnosis of influenza: state of the art. Clin. Lab. Med. 34: 365-385.

11. Yu, H., B. J. Cowling, L. Feng, E. H. Lau, Q. Liao, T. K. Tsang, Z. Peng, P. Wu, F. Liu, V. J. Fang, H. Zhang, M. Li, L. Zeng, Z. Xu, Z. Li, H. Luo, Q. Li, Z. Feng, B. Cao, W. Yang, J. T. Wu, Y. Wang, and G. M. Leung (2013) Human infection with avian influenza A H7N9 virus: an assessment of clinical severity. Lancet 382: 138-145.

12. Yan, Y. X., Y. M. Du, G. F. Wang, Y. X. Deng, R. Li, and K. S. Li (2016) The novel H7N9 influenza A virus NS1 induces p53mediated apoptosis of A549 cells. Cell Physiol. Biochem. 38: 1447-1458.

13. Liu, Q. T., Y. Z. Liu, J. Yang, X. M. Huang, K. K. Han, D. M. Zhao, K. R. Bi, and Y. Li (2016) Two genetically similar H9N2 influenza A viruses show different pathogenicity in mice. Front. Microbiol. 7.

14. Chan, R. W. Y., M. C. W. Chan, J. M. Nicholls, and J. S. M. Peiris (2013) Use of ex vivo and in vitro cultures of the human respiratory tract to study the tropism and host responses of highly pathogenic avian influenza A (H5N1) and other influenza viruses. Virus Res. 178: 133-145.

15. Shibata, T., T. Tanaka, K. Shimizu, S. Hayakawa, and K. Kuroda (2009) Immunofluorescence imaging of the influenza virus M1 protein is dependent on the fixation method. J. Virol. Methods 156: $162-165$.

16. Zhang, P. H., S. V. Vemula, J. Q. Zhao, B. C. Du, H. Mohan, J. K. Liu, H. S. El Mubarak, M. L. Landry, and I. Hewlett (2014) A highly sensitive europium nanoparticle-based immunoassay for detection of influenza A/B virus antigen in clinical specimens. $J$. Clin. Microbiol. 52: 4385-4387.

17. Bell, J., A. Bonner, D. M. Cohen, R. Birkhahn, R. Yogev, W. Triner, J. Cohen, E. Palavecino, and R. Selvarangan (2014) Multicenter clinical evaluation of the novel Alere (TM) $\mathrm{i}$ influenza A\&B isothermal nucleic acid amplification test. J. Clin. Virol. 61: 81-86.

18. Kubo, T., M. Agoh, L. Q. Mai, K. Fukushima, H. Nishimura, A. Yamaguchi, M. Hirano, A. Yoshikawa, F. Hasebe, S. Kohno, and K. Morita (2010) Development of a reverse transcription-loopmediated isothermal amplification assay for detection of pandemic (H1N1) 2009 virus as a novel molecular method for diagnosis of pandemic influenza in resource-limited settings. $J$. Clin. Microbiol. 48: 728-735.

19. Imai, M., A. Ninomiya, H. Minekawa, T. Notomi, T. Ishizaki, M. Tashiro, and T. Odagiri (2006) Development of H5-RT-LAMP (loop-mediated isothermal amplification) system for rapid diagnosis of $\mathrm{H} 5$ avian influenza virus infection. Vaccine 24: 6679-6682.

20. Imai, M., A. Ninomiya, H. Minekawa, T. Notomi, T. Ishizaki, P. V. Tu, N. T. K. Tien, M. Tashiro, and T. Odagiri (2007) Rapid diagnosis of $\mathrm{H} 5 \mathrm{~N} 1$ avian influenza virus infection by newly developed influenza H5 hemagglutinin gene-specific loop-mediated isothermal amplification method. J. Virol. Methods 141: 173-180. 21. Nakauchi, M., I. Takayama, H. Takahashi, M. Tashiro, and T. Kageyama (2014) Development of a reverse transcription loopmediated isothermal amplification assay for the rapid diagnosis of avian influenza A (H7N9) virus infection. J. Virol. Methods 204: 101-104.

22. Parida, M., J. Shukla, S. Sharma, S. R. Santhosh, V. Ravi, R. Mani, M. Thomas, S. Khare, A. Rai, R. K. Ratho, S. Pujari, B. Mishra, P. V. L. Rao, and R. Vijayaraghavan (2011) Development and evaluation of reverse transcription loop-mediated isothermal amplification assay for rapid and real-time detection of the swineorigin influenza A H1N1 virus. J. Mol. Diagn. 13: 100-107.

23. Laurie, K. L., P. Huston, S. Riley, J. M. Katz, D. J. Willison, J. S. Tam, A. W. Mounts, K. Hoschler, E. Miller, K. Vandemaele, E. Broberg, M. D. Van Kerkhove, and A. Nicoll (2013) Influenza serological studies to inform public health action: best practices to optimise timing, quality and reporting. Influenza Other Resp. 7: 211-224.

24. Krejcova, L., D. Hynek, V. Adam, J. Hubalek, and R. Kizek (2012) Electrochemical sensors and biosensors for influenza detection. Int. J. Electrochem. Sc. 7: 10779-10801.

25. van der Vries, E., J. Anber, A. van der Linden, Y. Wu, J. Maaskant, R. Stadhouders, R. van Beek, G. Rimmelzwaan, A. Osterhaus, C. Boucher, and M. Schutten (2013) Molecular assays for quantitative and qualitative detection of influenza virus and oseltamivir resistance mutations. J. Mol. Diagn. 15: 347-354.

26. Chen, L., Y. Tian, S. Chen, and O. Liesenfeld (2015) Performance of the cobas $((\mathrm{R}))$ influenza $\mathrm{A} / \mathrm{B}$ assay for rapid Pcr-based detection of influenza compared to prodesse ProFlu+ and viral culture. Eur. J. Microbiol. Immunol. (Bp) 5: 236-245.

27. Peaper, D. R. and M. L. Landry (2014) Neurovirology. In Handbook of Clinical Neurology, Elsevier, Amsterdam, The Netherlands.

28. Sutter, D. E., S. A. Worthy, D. M. Hensley, A. M. Maranich, D. M. Dolan, G. W. Fischer, and L. T. Daum (2012) Performance of five FDA-approved rapid antigen tests in the detection of 2009 H1N1 influenza A virus. J. Med. Virol. 84: 1699-1702.

29. Cho, C. H., M. K. Woo, J. Y. Kim, S. Cheong, C. K. Lee, S. A. An, C. S. Lim, and W. J. Kim (2013) Evaluation of five rapid diagnostic kits for influenza A/B virus. J. Virol. Methods 187: 51-56.

30. Hazelton, B., T. Gray, J. Ho, V. M. Ratnamohan, D. E. Dwyer, and J. Kok (2015) Detection of influenza A and B with the Alere (TM) i influenza A \& B: a novel isothermal nucleic acid amplification assay. Influenza Other Resp. 9: 151-154.

31. Wu, Z., W. J. Guo, Y. Y. Bai, L. Zhang, J. Hu, D. W. Pang, and Z. L. Zhang (2018) Digital single virus electrochemical enzymelinked immunoassay for ultrasensitive H7N9 avian influenza virus counting. Anal. Chem. 90: 1683-1690.

32. Chang, Y. F., W. H. Wang, Y. W. Hong, R. Y. Yuan, K. H. Chen, Y. W. Huang, P. L. Lu, Y. H. Chen, Y. M. A. Chen, L. C. Su, and S. F. Wang (2018) Simple strategy for rapid and sensitive detection of avian influenza A H7N9 virus based on intensitymodulated SPR biosensor and new generated antibody. Anal. Chem. 90: 1861-1869.

33. Sun, Y., L. Xu, F. D. Zhang, Z. G. Song, Y. W. Hu, Y. J. Ji, J. Y. Shen, B. Li, H. Z. Lu, and H. F. Yang (2017) A promising magnetic SERS immunosensor for sensitive detection of avian influenza virus. Biosens. Bioelectron. 89: 906-912.

34. Nidzworski, D., K. Siuzdak, P. Niedzialkowski, R. Bogdanowicz, M. Sobaszek, J. Ryl, P. Weiher, M. Sawczak, E. Wnuk, W. A. Goddard, A. Jaramillo-Botero, and T. Ossowski (2017) A rapidresponse ultrasensitive biosensor for influenza virus detection using antibody modified boron-doped diamond. Sci. Rep.-Uk. 7.

35. Leirs, K., P. T. Kumar, D. Decrop, E. Perez-Ruiz, P. Leblebici, B. Van Kelst, G. Compernolle, H. Meeuws, L. Van Wesenbeeck, O. Lagatie, L. Stuyver, A. Gils, J. Lammertyn, and D. Spasic 
(2016) Bioassay development for ultrasensitive detection of influenza A nucleoprotein using digital ELISA. Anal. Chem. 88: 8450-8458.

36. Lin, J. H., R. H. Wang, P. R. Jiao, Y. T. Li, Y. B. Li, M. Liao, Y. D. Yu, and M. H. Wang (2015) An impedance immunosensor based on low-cost microelectrodes and specific monoclonal antibodies for rapid detection of avian influenza virus $\mathrm{H} 5 \mathrm{~N} 1$ in chicken swabs. Biosens. Bioelectron. 67: 546-552.

37. Pang, Y. F., Z. Rong, J. F. Wang, R. Xiao, and S. Q. Wang (2015) A fluorescent aptasensor for $\mathrm{H} 5 \mathrm{~N} 1$ influenza virus detection based-on the core-shell nanoparticles metal-enhanced fluorescence (MEF). Biosens. Bioelectron. 66: 527-532.

38. Wang, R. H., L. J. Wang, Z. T. Callaway, H. G. Lu, T. J. Huang, and Y. B. Li (2017) A nanowell-based QCM aptasensor for rapid and sensitive detection of avian influenza virus. Sensor. Actuat. B-Chem. 240: 934-940.

39. Horiguchi, Y., T. Goda, A. Matsumoto, H. Takeuchi, S. Yamaoka, and Y. Miyahara (2017) Direct and label-free influenza virus detection based on multisite binding to sialic acid receptors. Biosens. Bioelectron. 92: 234-240.

40. Hai, W. F., T. Goda, H. Takeuchi, S. Yamaoka, Y. Horiguchi, A. Matsumoto, and Y. Miyahara (2018) Human influenza virus detection using sialyllactose-functionalized organic electrochemical transistors. Sensor. Actuat. B-Chem. 260: 635-641.

41. Cui, X. K., A. Das, A. N. Dhawane, J. Sweeney, X. H. Zhang, V. Chivukula, and S. S. Iyer (2017) Highly specific and rapid glycan based amperometric detection of influenza viruses. Chem. Sci. 8: 3628-3634.

42. Krejcova, L., L. Nejdl, M. A. M. Rodrigo, M. Zurek, M. Matousek, D. Hynek, O. Zitka, P. Kopel, V. Adam, and R. Kizek (2014) 3D printed chip for electrochemical detection of influenza virus labeled with $\mathrm{CdS}$ quantum dots. Biosens. Bioelectron. 54: 421-427.

43. Espy, M. J., T. F. Smith, M. W. Harmon, and A. P. Kendal (1986) Rapid detection of influenza virus by shell vial assay with monoclonal antibodies. J. Clin. Microbiol. 24: 677-679.

44. Zitterkopf, N. L., S. Leekha, M. J. Espy, C. M. Wood, P. Sampathkumar, and T. F. Smith (2006) Relevance of influenza a virus detection by PCR, shell vial assay, and tube cell culture to rapid reporting procedures. J. Clin. Microbiol. 44: 3366-3367.

45. Notomi, T., H. Okayama, H. Masubuchi, T. Yonekawa, K. Watanabe, N. Amino, and T. Hase (2000) Loop-mediated isothermal amplification of DNA. Nucleic Acids Res. 28: E63.

46. Tomita, N., Y. Mori, H. Kanda, and T. Notomi (2008) Loopmediated isothermal amplification (LAMP) of gene sequences and simple visual detection of products. Nat. Protoc. 3: 877-882.

47. Poon, L. L., C. S. Leung, K. H. Chan, J. H. Lee, K. Y. Yuen, Y. Guan, and J. S. Peiris (2005) Detection of human influenza A viruses by loop-mediated isothermal amplification. J. Clin. Microbiol. 43: 427-430.

48. Wu, L. T., M. D. Curran, J. S. Ellis, S. Parmar, A. V. Ritchie, P. I. Sharma, J. P. Allain, H. Jalal, M. Zambon, and H. H. Lee (2010) Nucleic acid dipstick test for molecular diagnosis of pandemic H1N1. J. Clin. Microbiol. 48: 3608-3613.

49. Wu, L. T., I. Thomas, M. D. Curran, J. S. Ellis, S. Parmar, N. Goel, P. I. Sharma, J. P. Allain, and H. H. Lee (2013) Duplex molecular assay intended for point-of-care diagnosis of influenza A/B virus infection. J. Clin. Microbiol. 51: 3031-3038.

50. Ellis, J. S. and M. C. Zambon (2002) Molecular diagnosis of influenza. Rev. Med. Virol. 12: 375-389.

51. Hibbitts, S. and F. D. Fox (2002) The application of molecular techniques to diagnosis of viral respiratory tract infections. Rev. Med. Microbiol. 13: 177-185.

52. Deiman, B., P. van Aarle, and P. Sillekens (2002) Characteristics and applications of nucleic acid sequence-based amplification (NASBA). Mol. Biotechnol. 20: 163-179.
53. Moore, C., S. Hibbitts, N. Owen, S. A. Corden, G. Harrison, J. Fox, C. Gelder, and D. Westmoreland (2004) Development and evaluation of a real-time nucleic acid sequence based amplification assay for rapid detection of influenza A. J. Med. Virol. 74: 619-628.

54. Ge, Y. Y., L. B. Cui, X. Qi, J. Shan, Y. F. Shan, Y. H. Qi, B. Wu, H. Wang, and Z. Y. Shi (2010) Detection of novel swine origin influenza A virus (H1N1) by real-time nucleic acid sequencebased amplification. J. Virol. Methods 163: 495-497.

55. Wang, J. J., W. Tai, S. L. Angione, A. R. John, S. M. Opal, A. W. Artenstein, and A. Tripathia (2013) Subtyping clinical specimens of influenza A virus by use of a simple method to amplify RNA targets. J. Clin. Microbiol. 51: 3324-3330.

56. Stephenson, I., A. Heath, D. Major, R. W. Newman, K. Hoschler, W. Junzi, J. M. Katz, J. P. Weir, M. C. Zambon, and J. M. Wood (2009) Reproducibility of serologic assays for influenza virus A (H5N1). Emerg. Infect. Dis. 15: 1250-1259.

57. Gordon, A., E. Videa, S. Saborio, R. Lopez, G. Kuan, A. Balmaseda, and E. Harris (2010) Diagnostic accuracy of a rapid influenza test for pandemic influenza A H1N1. PLoS One 5.

58. Drexler, J. F., A. Helmer, H. Kirberg, U. Reber, M. Panning, M. Muller, K. Hofling, B. Matz, C. Drosten, and A. M. Eis-Hubinger (2009) Poor clinical sensitivity of rapid antigen test for influenza A pandemic (H1N1) 2009 virus. Emerg. Infect. Dis. 15: 1662-1664.

59. van Elden, L. J. R., M. Nijhuis, P. Schipper, R. Schuurman, and A. M. van Loon (2001) Simultaneous detection of influenza viruses $\mathrm{A}$ and $\mathrm{B}$ using real-time quantitative PCR. J. Clin. Microbiol. 39: 196-200.

60. Grabowska, I., K. Malecka, A. Stachyra, A. Gora-Sochacka, A. Sirko, W. Zagorski-Ostoja, H. Radecka, and J. Radecki (2013) Single electrode genosensor for simultaneous determination of sequences encoding hemagglutinin and neuraminidase of avian influenza virus type H5N1. Anal. Chem. 85: 10167-10173.

61. Dong, S. B., R. T. Zhao, J. G. Zhu, X. Lu, Y. Li, S. F. Qiu, L. L. Jia, X. Jiao, S. P. Song, C. H. Fan, R. Z. Hao, and H. B. Song (2015) Electrochemical DNA biosensor based on a tetrahedral nanostructure probe for the detection of avian influenza A (H7N9) virus. ACS Appl. Mater. Inter. 7: 8834-8842.

62. Pei, H., N. Lu, Y. L. Wen, S. P. Song, Y. Liu, H. Yan, and C. H. Fan (2010) A DNA nanostructure-based biomolecular probe carrier platform for electrochemical biosensing. Adv. Mater. 22: 4754-4758.

63. Li, Z. H., B. Zhao, D. F. Wang, Y. L. Wen, G. Liu, H. Q. Dong, S. P. Song, and C. H. Fan (2014) DNA nanostructure-based universal microarray platform for high-efficiency multiplex bioanalysis in biofluids. ACS Appl. Mater. Inter. 6: 17944-17953.

64. Malecka, K., A. Stachyra, A. Gora-Sochacka, A. Sirko, W. Zagorski-Ostoja, W. Dehaen, H. Radecka, and J. Radecki (2015) New redox-active layer create via epoxy-amine reaction - The base of genosensor for the detection of specific DNA and RNA sequences of avian influenza virus H5N1. Biosens. Bioelectron. 65: 427-434.

65. Lee, J., M. Morita, K. Takemura, and E. Y. Park (2018) A multifunctional gold/iron-oxide nanoparticle-CNT hybrid nanomaterial as virus DNA sensing platform. Biosens. Bioelectron. 102: 425-431.

66. Han, Z. J., D. H. Seo, S. Yick, J. H. Chen, and K. Ostrikov (2014) $\mathrm{MnOx} /$ carbon nanotube/reduced graphene oxide nanohybrids as high-performance supercapacitor electrodes. NPG Asia Mater. 6.

67. Fu, Y. C., Z. Callaway, J. Lum, R. H. Wang, J. H. Lin, and Y. B. Li (2014) Exploiting enzyme catalysis in ultra-low ion strength media for impedance biosensing of avian influenza virus using a bare interdigitated electrode. Anal. Chem. 86: 1965-1971.

68. de Graaf, M. and R. A. M. Fouchier (2014) Role of receptor binding specificity in influenza A virus transmission and pathogenesis. EMBO J. 33: 823-841.

69. Air, G. M. (2014) Influenza virus-glycan interactions. Curr. Opin. Virol. 7: 128-133.

70. Hushegyi, A., D. Pihikova, T. Bertok, V. Adam, R. Kizek, and 
J. Tkac (2016) Ultrasensitive detection of influenza viruses with a glycan-based impedimetric biosensor. Biosens. Bioelectron. 79: 644-649.

71. Hushegyi, A., T. Bertok, P. Damborsky, J. Katrlik, and J. Tkac (2015) An ultrasensitive impedimetric glycan biosensor with controlled glycan density for detection of lectins and influenza hemagglutinins. Chem. Commun. 51: 7474-7477.

72. Anik, U., Y. Tepeli, M. Sayhi, J. Nsiri, and M. F. Diouani (2018) Towards the electrochemical diagnostic of influenza virus: development of a graphene-Au hybrid nanocomposite modified influenza virus biosensor based on neuraminidase activity. Analyst 143: $150-156$

73. Nebel, C. E., N. Yang, H. Uetsuka, E. Osawa, N. Tokuda, and O. Williams (2009) Diamond nano-wires, a new approach towards next generation electrochemical gene sensor platforms. Diam. Relat. Mater. 18: 910-917.

74. Qureshi, A., W. P. Kang, J. L. Davidson, and Y. Gurbuz (2009) Review on carbon-derived, solid-state, micro and nano sensors for electrochemical sensing applications. Diam. Relat. Mater. 18: 1401-1420.

75. Enache, T. A. and A. M. Oliveira-Brett (2011) Boron doped diamond and glassy carbon electrodes comparative study of the oxidation behaviour of cysteine and methionine. Bioelectrochemistry 81: 46-52.

76. Wu, Z., C. H. Zhou, L. J. Pan, T. Zeng, L. Zhu, D. W. Pang, and Z. L. Zhang (2016) Reliable digital single molecule electrochemistry for ultrasensitive alkaline phosphatase detection. Anal. Chem. 88: 9166-9172.

77. Wang, T. Y., M. Zhang, D. D. Dreher, and Y. Zeng (2013) Ultrasensitive microfluidic solid-phase ELISA using an actuatable microwell-patterned PDMS chip. Lab Chip 13: 4190-4197.

78. Sayhi, M., O. Ouerghi, K. Belgacem, M. Arbi, Y. Tepeli, A. Ghram, U. Anik, L. Osterlund, D. Laouini, and M. F. Diouani (2018) Electrochemical detection of influenza virus H9N2 based on both immunomagnetic extraction and gold catalysis using an immobilization-free screen printed carbon microelectrode. Biosens. Bioelectron. 107: 170-177.

79. Jarocka, U., R. Sawicka, A. Gora-Sochacka, A. Sirko, W. ZagorskiOstoja, J. Radecki, and H. Radecka (2014) Electrochemical immunosensor for detection of antibodies against influenza A virus H5N1 in hen serum. Biosens. Bioelectron. 55: 301-306.

80. Le, T. T., P. X. Chang, D. J. Benton, J. W. McCauley, M. Iqbal, and A. E. G. Cass (2017) Dual recognition element lateral flow assay toward multiplex strain specific influenza virus detection. Anal. Chem. 89: 6781-6786.

81. Park, H. J., S. C. Yang, and J. Choo (2016) Early diagnosis of influenza virus A using surface-enhanced raman scattering-based lateral flow assay. B Korean Chem. Soc. 37: 2019-2024.

82. Wiriyachaiporn, N., H. Sirikett, W. Maneeprakorn, and T. Dharakul (2017) Carbon nanotag based visual detection of influenza A virus by a lateral flow immunoassay. Microchim. Acta 184: 1827-1835.

83. Zhou, C. H., J. Y. Zhao, D. W. Pang, and Z. L. Zhang (2014) Enzyme-induced metallization as a signal amplification strategy for highly sensitive colorimetric detection of avian influenza virus particles. Anal. Chem. 86: 2752-2759.

84. Ahmed, S. R., J. Kim, T. Suzuki, J. Lee, and E. Y. Park (2016) Enhanced catalytic activity of gold nanoparticle-carbon nanotube hybrids for influenza virus detection. Biosens. Bioelectron. 85: 503-508.

85. Lin, C. Y., Y. J. Guo, M. M. Zhao, M. Sun, F. Luo, L. H. Guo, B. Qiu, Z. Y. Lin, and G. N. Chen (2017) Highly sensitive colorimetric immunosensor for influenza virus H5N1 based on enzyme-encapsulated liposome. Anal. Chim. Acta 963: 112-118.

86. Le, T. T., B. Adamiak, D. J. Benton, C. J. Johnson, S. Sharma, R. Fenton, J. W. McCauley, M. Iqbal, and A. E. G. Cass (2014) Aptamer-based biosensors for the rapid visual detection of flu viruses. Chem. Commun. 50: 15533-15536.

87. Loo, J. F. C., S. S. Wang, F. Peng, J. A. He, L. He, Y. C. Guo, D. Y. Gu, H. C. Kwok, S. Y. Wu, H. P. Ho, W. D. Xie, Y. H. Shao, and S. K. Kong (2015) A non-PCR SPR platform using RNase H to detect MicroRNA 29a-3p from throat swabs of human subjects with influenza A virus H1N1 infection. Analyst 140: 4566-4575.

88. Huang, C. J., Z. E. Lin, Y. S. Yang, H. W. H. Chan, and W. Y. Chen (2018) Neutralized chimeric DNA probe for detection of single nucleotide polymorphism on surface plasmon resonance biosensor. Biosens. Bioelectron. 99: 170-175.

89. Wang, R. H. and Y. B. Li (2013) Hydrogel based QCM aptasensor for detection of avian influenza virus. Biosens. Bioelectron. 42: 148-155.

90. Wangchareansak, T., C. Sangma, P. Ngernmeesri, A. Thitithanyanont, and P. A. Lieberzeit (2013) Self-assembled glucosamine monolayers as biomimetic receptors for detecting WGA lectin and influenza virus with a quartz crystal microbalance. Anal. Bioanal. Chem. 405: 6471-6478. 